Original Artide

\title{
Evaluation of Chemical, Nutritional and Antioxidant Characteristics of Roselle (Hibiscus sabdariffa L.) Seed
}

\author{
Zohreh Mokhtari Nasrabadi $^{1}$, Soheila Zarringhalami ${ }^{1 *}$, Ali Ganjloo ${ }^{1}$ \\ 1- Department of Food Science and Technology, Faculty of Agriculture, University of Zanjan, Zanjan, Iran.
}

\section{A B S T R A C T}

Background and Objectives: Roselle (Hibiscus sabdariffa L.) is one of the valuable plants grown in tropical and subtropical regions such as some parts of Iran. Roselle calyces are commonly used to make herbal tea as well as a natural food color additive. However, Roselle seeds are usually discarded as by-products, while they can be used as a source of nutritious and functional compound. Therefore, in the current study, some of the chemical and nutritional characteristics of Iranian Roselle seed were investigated. In addition, the effects of different extracting solvents on seed extraction yield, total phenol content (TPC) and antioxidant activity (scavenging ability) of the extracts were evaluated.

Materials and Methods: Some chemical and nutritional properties of Roselle seeds such as moisture, protein, total fiber and lipid contents were determined. Also, fatty acid composition of the oil was determined using gas chromatography. The effects of different solvents including acetone, methanol and water, on yield, TPC (Folin-Ciocalteu assay) and antioxidant activity (DPPH and ABTS methods) of Roselle seeds were also investigated.

Results: The results showed that the Roselle seeds are the main sources of protein, lipid and fiber $(26.62 \pm 0.03 \%$, $21.03 \pm 0.02 \%$ and $19.81 \pm 0.01 \%$, respectively). Linoleic $(41.06 \pm 0.7 \%)$, oleic $(27.07 \pm 0.01 \%)$ and palmitic $(21.9 \pm 0.03 \%)$ acids are the main fatty acids in the Roselle seeds oil. The maximum yield $(20 \pm 0.02 \%)$, related to aqueous extract, however, higher TPC $(201 \pm 0.02 \mathrm{mg}$ GAEs/100 g) and antioxidant activity (DPPH, $94.15 \pm 0.2 \%$; ABTS, $75.91 \pm 0.03 \%)$ were observed in acetone extract.

Conclusions: According to the results, Roselle seeds are a good source of protein, fiber and oil, which contains unsaturated fatty acids especially linoleic acid. In addition, the acetone extract showed the highest TPC and antioxidant activity among other extracts.

Keywords: Antioxidant activity, Chemical and nutritional characteristics, Roselle seed, Total phenols

\section{Introduction}

Roselle (Hibiscus sabdariffa L.) plant belongs to the Malvaceae family, which is widely grown in tropical and subtropical regions around the world (1). It is also known as Roselle, Sorele, Mesta or Karkade (2). Iran is not the main origin of this plant, but it is mostly grown in tropical and subtropical parts of Iran, such as the Sistan and Baluchestan province. Roselle plant is also known as Maki tea, sour tea and red tea in Iran (3). Due to the good taste and color, dried calyces are used for tea, jelly, marmalade, ice cream, sorbets, butter, pies, sauces, tarts and other desserts. However, the seeds are usually discarded as waste, while numerous studies have shown that these seeds can be very nutritious $(4,5,6)$. However, in West Africa, seeds are traditionally used as roasted coffee due to their special flavor. It is also used in China and Sudan for extracting edible oils $(7,8)$. Therefore, the study on Roselle seed has attracted several researchers in the recent years. Today, plant protein sources are of great interest and many studies have been done on the nutritional characteristics of vegetable seeds as unconventional sources of protein $(9,10)$. El-Adawy and Khalil (1994) showed that the proteins of Roselle seeds contain essential amino acids such as lysine, valine, isoleucine, threonine, tryptophan and leucine (11). Mohamed et al. (2007) showed that Roselle seed is a rich source of protein and antioxidants, including vitamin E. It is also reported that Roselle seed oil is rich in phytosterols and tocopherols, in particular beta-cytosestrol and 
gamma-tocopherol (12). Eltayeib and Elaziz (2014) showed that the Roselle seed is a rich source of oil $(21.1 \%)$ containinbg oleic and linoleic acids as the main unsaturated fatty acids (13).

Since, the Roselle seed calyces in Iran are used as herbal tea and the seeds are discarded as waste, the objectives of the current study were to investigate of some the chemical and nutritional characteristics of Roselle seed and evaluate the effect of different solvents including acetone, methanol and water on the extraction yield, TPC and antioxidant activity of Roselle seed extracts.

\section{Materials and Methods}

Materials: Roselle (Hibiscus sabdariffa L.) seeds were obtained from Agricultural Research Center, Sistan-Baluchestan province, Iran. All reagents and solvents used in this study were purchased from Merck (Darmstadt, Germany).

Preparation of Roselle seed powder : Roselle seeds were cleaned and rinsed with tap water. The seeds were oven dried at $60^{\circ} \mathrm{C}$ (moisture content $10 \%$ ). Then, the dried seeds were milled (Porten, Sweden) and powder was sieved through a $60-$ mesh screen until the fine Roselle seed powder was obtained (1).

Chemical and nutritional analysis of Roselle seeds: Moisture, protein (micro-Kjeldahl), oil (Soxhlet) and total fiber contents were determined using the AOCS (1997) Methods Ba 2a-38, Ba 4d-90, Ba 3-38 and Ba 6-84, respectively (14). Fatty acids composition of the seed oil was performed using gas chromatography (GC) on a fused-silica capillary column (BPX70 30 $\mathrm{m} \times 0.25 \mathrm{~mm}$ i.d and $0.22 \mathrm{~mm}$ film thickness, SGE, Melbourne, Australia), according to Zarringhalami et al., 2014 (15).

Extraction method: Extracting solvents including de-ionized water, acetone and methanol were added at $20 \mathrm{~mL}$ content to $1 \mathrm{~g}$ of Roselle seed powder, then gently stired and filtered. Each filtrate obtained was collected into a graduated cylinder and the volume adjusted to $20 \mathrm{~mL}$ with the same extracting solvent in order to estimate the TPC and antioxidant activity (16).

Extraction yield: The extraction yield of the Roselle seed powder was calculated according to the equation below(20).

(Equation 1):

Extraction yield $\%=\left(\mathrm{m}_{2} / \mathrm{m}_{1}\right) \times 100$ where $m_{1}$ is mass of the dry matter and $m_{2}$ is mass of the extract.

TPC determination: TPC of the Roselle seed extracts was calorimetrically estimated using the Folin-Ciocalteu method according to Sultana et al. (2009), with slight modifications (17). Briefly, 0.04 $\mathrm{mL}$ of each crude extract was mixed with $0.2 \mathrm{~mL}$ Folin- Ciocalteu reagent. After $3 \mathrm{~min}, 1 \mathrm{~mL}$ of saturated sodium carbonate solution was added to the mixture and adjusted to $10 \mathrm{~mL}$ by distilled water. The mixture was incubated at $45^{\circ} \mathrm{C}$ for $30 \mathrm{~min}$ and cooled to room temperature. Then, the absorbance of the prepared samples was measured with a spectrophotometer (Shimadzu UV-2550; Shimadzu, Kyoto, Japan) at $725 \mathrm{~nm}$. The results are expressed as $\mathrm{mg}$ of gallic acid equivalents/100 $\mathrm{g}$ of extract (mg GAEs/100 g).

Radicals scavenging activity: The radical scavenging ability of the extracts was determined using the stable DPPH free radical (2, 2-diphenyl-1picrylhydrazyl) according to Nyam et al. (2014) with some modification (4). The extract solutions $(0.3 \mathrm{~mL})$ were mixed with $2.7 \mathrm{~mL}$ of a freshly prepared DPPH solution $\left(6 \times 10^{-5} \mathrm{M}\right.$ in $95 \%$ methanol). The mixture was shaken vigorously and left at room temperature for $60 \mathrm{~min}$ in the dark until stable absorbance values were obtained. The control contained methanol in place of the sample. The change in the absorbance of the extracts measured at $517 \mathrm{~nm}$ using a spectrophotometer. The percentage inhibition of the DPPH radicals was calculated using the equation below.

(Equation 2)

DPPH scavenging activity $(\%)=\left[\left(\mathrm{A}_{\mathrm{c}}-\mathrm{A}_{\mathrm{s}}\right) / \mathrm{A}_{\mathrm{c}}\right] \times 100$

where $A_{c}$ and $A_{s}$ are the absorbance of the blank (control) and samples, respectively.

The 2,2'-azino-di-(3-ethylbenzothiazoline-6 sulphonic acid (ABTS) radical scavenging activity was also determined as described by Ahmed et al (2015) (18). ABTS free radical $\left(\mathrm{ABTS}^{\circ+}\right)$ was generated by reacting $7.4 \mathrm{mM}$ ABTS (ABTS dissolved in deionized water to $7.4 \mathrm{mM}$ concentration) and $2.6 \mathrm{mM}$ potassium persulphate aqueous solution, as the oxidant agent, at a ratio of $1: 1(\mathrm{v} / \mathrm{v})$. The mixture was kept at room temperature in the dark for $12 \mathrm{~h}$. Prior to assay, $\mathrm{ABTS}^{\circ+}$ working solution was prepared by diluting the stock solution in methanol to obtain an 
absorbance of $1.1( \pm 0.02)$ at $734 \mathrm{~nm} .150 \mu \mathrm{L}$ of diluted sample $(2 \mathrm{mg} / \mathrm{mL})$, was mixed with $2850 \mu \mathrm{L}$ of ABTS $^{*+}$ solution. The absorbance was then read at $734 \mathrm{~nm}$ after $2 \mathrm{~h}$ of incubation in the dark, at room temperature. The blank (control) was prepared in the same manner, except that methanol was used instead of the sample. The percentage reduction of $\mathrm{ABTS}^{\circ+}$ to ABTS was calculated according to the equation blow: (equation 3)

ABTS radical scavenging activity $(\%)=\left[\left(\mathrm{A}_{\mathrm{c}}-\mathrm{A}_{\mathrm{s}}\right) / \mathrm{A}_{\mathrm{c}}\right] \times 100$

where $A_{c}$ and $A_{s}$ are the absorbance of the blank (control) and samples, respectively.

Statistical analysis: Experimental results were analyzed by SPSS version 16.0 (SPSS Inc. Chicago, IL). Differences between means obtained from 3 replicates were determined using one-way ANOVA and Duncan's test. The level of statistical significance was $\mathrm{P} \leq 0.05$.

\section{Results}

\section{Chemical and nutritional properties of Roselle} seeds: The results of moisture, protein, fiber and oil contents of Roselle seed are presented in Table 1. The results obtained showed that Roselle seed is considered as a valuable source of protein, dietary fiber and oil. According to the results which are shown in Table 2, $68.85 \pm 0.6 \%$ of Roselle seed oil fatty acids are unsaturated and linoleic acid $(41.06 \pm 0.7 \%)$ is the major unsaturated fatty acid in the Roselle seed oil.

Table1. Chemical and nutritional characteristics (\%) of Roselle seeds

\begin{tabular}{lcccc}
\hline \multicolumn{5}{c}{ Characteristics } \\
\hline Sample & Moisture & Oil & Protein & Crude fiber \\
\hline $\begin{array}{l}\text { Roselle seed } \\
\text { powder }\end{array}$ & $6.32 \pm 0.01$ & $21.03 \pm 0.02$ & $26.62 \pm 0.03$ & $19.81 \pm 0.01$ \\
\hline $\begin{array}{l}\text { Each value in the table shows the mean } \pm \text { standard deviation of triplicate } \\
\text { analysis. }\end{array}$ & & &
\end{tabular}

Table2. Fatty acid composition of Roselle seeds (\%)

\begin{tabular}{lc}
\hline Fatty acids & Content $(\%)$ \\
\hline Myristic acid (C14:0) & $0.85 \pm 0.03$ \\
Palmitic acid (C16:0) & $21.90 \pm 0.03$ \\
Stearic acid (C18:0) & $5.34 \pm 0.04$ \\
Oleic acid (C18:1) & $27.07 \pm 0.01$ \\
Linoleic acid (C18:2) & $0.07 \pm 41.06$ \\
$\alpha-$ Linolenic (C18:3) & $0.72 \pm 0.02$ \\
Others & $3.06 \pm 0.04$ \\
\hline
\end{tabular}

Each value in the table shows the mean \pm standard deviation of triplicate analysis.

\section{Extraction yield, TPC and antioxidant activity of} Roselle seeds: TPC and antioxidant activity (DPPH and ABTS methods) of the Roselle seed extracts are shown in Fig 1 and 2. According to the results, the acetone extract provided the highest TPC, DPPH and ABTS radical scavenging activity, while the lowest was related to the aqueous extract, however, the maximum extraction yield (Table 3), related to this extract.

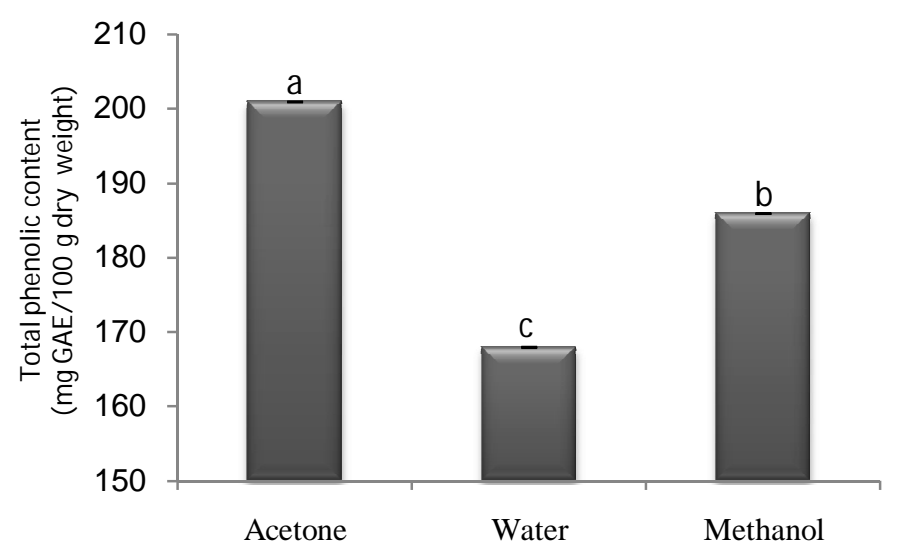

Fig1. Total phenolic content (mg GAE/100 g dry weight) of different extracts of Roselle seed powder.

Each value in the figure shows the mean \pm standard deviation of triplicate analysis. Different letters represent a significant difference at $p<0.05$.
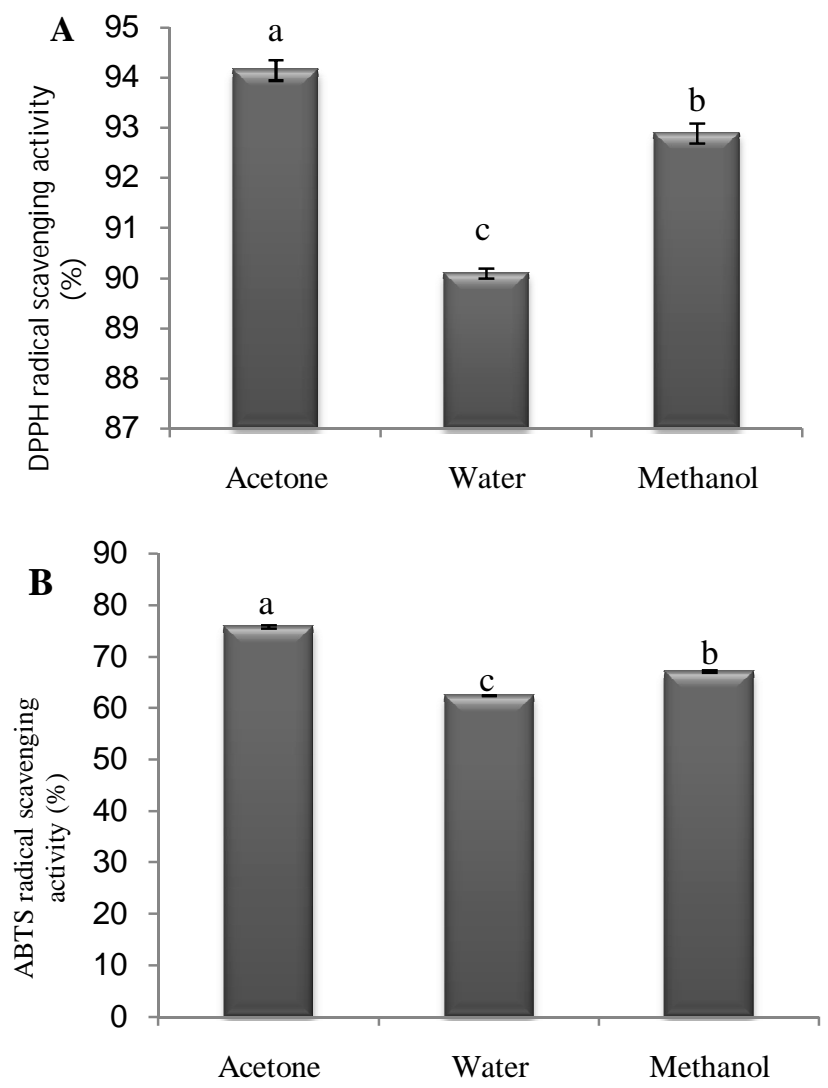

Fig 2. DPPH (A) and ABTS (B) radical scavenging activities (\%) of different extracts.

Each value in the figure shows the mean \pm standard deviation of triplicate analysis. Different letters represent a significant difference at $\mathrm{p}<0.05$. 
Table 3. Effect of the used solvents with different polarities on the extraction yield

\begin{tabular}{lcc}
\hline Solvent & Polarity Index & Extraction yield (\%) \\
\hline Water & 9 & $20 \pm 0.02^{\mathrm{a}}$ \\
Acetone & 5.1 & $15 \pm 0.10^{\mathrm{c}}$ \\
Methanol & 5.1 & $17 \pm 0.04^{\mathrm{b}}$ \\
\hline
\end{tabular}

Each value in the table shows the mean \pm standard deviation of triplicate analysis. Different letters represent a significant difference at $\mathrm{p}<0.05$.

\section{Disc ussion}

Chemical and nutritional compounds of Roselle seeds: According to the results in Table 1 , the amount of moisture of the Roselle seeds was $6.32 \pm 0.01 \%$, which indicates that it can be stored for a long period of time without qualitative damages (21). This moisture content is also suitable for future analysis. Roselle seed is also a good plant source of protein $(26.62 \pm 0.03 \%)$ and lipid $(21.03 \pm 0.02 \%)$. Our results are in agreement with the findings of previous researche conducted by Tounkara et al. (2011), Halimatul et al. (2007), Anel et al (2016) and Mariod et al. (2013) (1, 22, 23,24). The amount of fiber obtained from Roselle seed in the current research was $19.81 \pm 0.01 \%$ (Table 1). While Hainida et al. (2008) reported that the amount of fiber in Roselle seed is $19.2 \%$ (25). For many years, fibers have been considered as useful compounds for health. Fiber improves the gastrointestinal motility, changes the concentration of insulin and hormones by fermentation in the small intestine and the production of short chain fatty acids; thereby reducing the risk of colon cancer, diabetes and blood cholesterol (25).

The results of fatty acids determination of Roselle seed oil (Table 2) show that linoleic acid (41.06 \pm $0.07 \%)$, oleic acid $(27.07 \pm 0.01 \%)$ and palmitic acid $(21.90 \pm 0.03 \%)$ are the main fatty acids in the oil. In general, approximately $68.85 \%$ of the fatty acids are unsaturated and $28.09 \%$ of them are saturated. Linoleic acid is one of the most important fatty acids that have beneficial effects on reducing blood pressure and cholesterol levels (26). Therefore, the high amounts, would increase the nutritional value of the oil. Similar results had previously reported by Atat and Imaizumi (2002); Mohamed et al. (2007) and Rehab and Ayman (2017), who observed that linoleic, oleic and palmitic acids were the most important fatty acids in the Roselle seed oil $(27,13,28)$. In another study, which was done by Elneairy (2014), the fatty acid composition of two species of Roselle seeds (Egypt and Libya) was compared. The results showed that the amounts of linoleic, oleic, palmitic and stearic acids of the oil obtained from the Egyptian species were 38.17, $33.31,18.15$ and $4.09 \%$, respectively, while their amounts in the oil extracted from Libya species were $17.50,16.50,12.70$ and $15.97 \%$, respectively (29). It is important to note that differences between the amount of fatty acids obtained in the present study and that of the previous studies can be due to differences in species, climatic and environmental conditions, and the maturity period of the plant, which can affect the amount and ratio of fatty acids (15).

Extraction yield, TPC and antioxidant activity of Roselle seeds: The extraction efficiency is affected by the chemical nature of phytochemicals, the extraction method used, particle size of samples, type of solvents used, as well as the presence of interfering substances (19). The extraction yield also depends on the solvent polarity, $\mathrm{pH}$, temperature, extraction time, and composition of the sample. Under the same extraction time and temperature, solvent and sample composition are known as the most important parameters (20). In this work, extraction yield of Roselle seed was obtained using water, acetone and methanol as shown in Table 3. The results obtained showed that the maximum extraction yield was related to water $(20 \pm 0.02 \%)$ then methanol $(17 \pm 0.04 \%)$ and acetone $(15 \pm 0.1 \%)$. It can be due to different polarities of the used solvents in such a way that when the polarity of the solvent decreased (water > methanol and acetone) the extraction yield values decreased in the same order (30).

The Folin-Cioalteau assay is a simple and widespread method which is used for the TPC determination of natural products (31). In addition, DPPH method is used to measure the antioxidant activity of various plant extracts, but due to the close similarity of environmental conditions of the ABTS test to physiological conditions, as well as electron transfer with higher velocity, this test is often used along with the DPPH method (32). TPC, DPPH and ABTS free radicals scavenging activities of the Roselle seeds are shown in Fig. 1 and 2, respectively. According to the results, acetone extract showed the highest amount of TPC with $201 \pm 0.02 \mathrm{mg} \mathrm{GAE} / 100 \mathrm{~g}$. While, the lowest amount of TPC related to aqueous extract with $1.67 \pm 0.05 \mathrm{mg} \mathrm{GAE} / 100 \mathrm{~g}$. Furthermore, the extracts with the highest TPC showed the highest antioxidant activity which determined by DPPH and ABTS methods $(94.15 \pm 0.2 \%$ and $75.91 \pm 0.03 \%$, 
respectively) and the lowest value was obtained from water extract $(90.1 \pm 0.1 \%$ and $62.52 \pm 0.1 \%$, . Therefore, the solvents used had a significant effect on TPC and antioxidant activity $(\mathrm{P}<0.05)$. Since, TPC of the plant materials may contribute directly to the antioxidant activity (33), the highest antioxidant activity of acetone extract compared with the other extracts is expected. However, some studies show the negative or the weak correlation between TPC and $\mathrm{DPPH}^{`}$ radical scavenging activity. This result may be due to the fact that the Folin-Ciocalteau assay gives a crude estimate of the TPC of an extract, whereas the free radical scavenging assay is not only specific to polyphenols. In addition, different types of phenol compounds have different antioxidant activities which mainly depends on their structure (34). Therefore, the findings of experiments in this field depend on the type of plant source, phenol compounds and extracted solvents $(35,36)$. This result was in accordance with those obtained by Rimamcwe and Chavan (2017) as well as Cissouma et al. (2013), who investigated that the effects of various solvents on the antioxidant activity of Roselle seed extract, reportingthat the acetone extract of Roselle seed powder showed the most antioxidant activity.

\section{Conclusion}

The results of the current study indicated that Roselle seed is a valuable nutrient source containing high amounts of protein $(26.62 \pm 0.03 \%)$, dietary fiber $(19.81 \pm 0.01 \%)$ and oil $(21.03 \pm 0.02 \%)$ with mostly unsaturated fatty acids. Linoleic acid, which has beneficial effects on reducing blood cholestrol levels and blood pressure, is determined as the major fatty acid $(41.06 \pm 0.07 \%)$ in Roselle seed oil. Also, according to the results, the extracting solvent had a significant effect on the extraction yield, TPC, DPPH and ABTS free radical scavenging activity $(\mathrm{P}<0.05)$. The maximum extraction yield was obtained using water $(20 \pm 0.02 \%)$, methanol $(17 \pm 0.04 \%)$ and acetone $(15 \pm 0.1 \%)$. However, the extract with the highest TPC and antioxidant activity were obtained with acetone. Generally, considering the application, Roselle seeds can be used as a valuable nutritional sorce in the food industry.

\section{Financial disclosure}

The authors declared no financial interest.

\section{Funding/Support}

This work was financially supported by University of Zanjan.

\section{References}

1. Tounkara F, Amadou I, Le GL, Shi, YH. Effect of boiling on the physicochemical properties of Roselle seeds (Hibiscus sabdariffa L.) cultivated in Mali. Afr J Biotechnol 2011; 10(79): 18160-18166.

2. Koehler HH, Chang IH, Scheier G, Burke W. Nutrition composition, protein quality and sensory properties of thirty-six cultivars of dry beans ( $P$. vulgaris). J Food Sci 1987; 52: 1335-1340.

3. Parsa MB, Rezvani Moghaddam P, Ghorbani R, Azami Sardooei Z. The effect of sowing and plant density on yield and yield components of Roselle (Hibiscus sabdariffa L.) under Jiroft climate conditions. Ira J Field Crops Res 1395; 14(4): 735-745. [In Persian].

4. Nyam K, Leao SY, Tan CP, Long K. Functional properties of Roselle (Hibiscus sabdariffa L.) seed and its application as bakery product. J Food Sci Technol 2014; 51(12): 3830-3837.

5. Shaheen MA, El-Nakhlawy F, Al-Shareef AR. Roselle (Hibiscus sabdariffa L.) seeds as unconventional nutritional source. Afr J Biotechnol 2012; 11(41): 9821-9824.

6. Elkhalifa AE, Mohamed MA, Agab M. Biochemical investigation on hibiscus sabdariffa 1.(karkade) seedbased sudanese fermented food locally known as furundu. Electron. J Environ Agric Food Chem 2011; 11(03): 265-278.

7. Tran-Thi NY, Kasim NS, Yuliana M, Huynh LH, Chang WL, Ju YH. Polysaccharides-induced precipitation of protein from defatted Roselle seed and its characterization: Antinutritional factors and functional properties. J Taiwan Inst Chem Eng 2013; 44(2): 152155.

8. Bertagnolli SM, Silveira ML, Fogaça AD, Umann L, Penna NG. Bioactive compounds and acceptance of cookies made with Guava peel flour. J Food Sci Technol 2014; 34: 303-308.

9. Rao N, Prabhakara PG, Rao G. Preparation of wood apple (Feronia limonia L.) seed protein concentrate and evaluation of its nutritional and functional characteristics. Int Food Res J 2011; 18(3): 949-955.

10. Oluwafemi R. Palm kernel cake (PKC) utilization in monogastic animal feeding implications for sustainable livestock development. J Vet Med 2009; 6(2): 1-8.

11. El-Adawy TA, Khalil AH. Characteristics of Roselle seeds as a new source of protein and lipid. J Agric Food Chem 1994; 42(9): 1896-1900.

12. Mohamed R, Fern Andez M, Aguilar M. Roselle (Hibiscus sabdariffa) seed oil is a rich source of $\gamma-$ tocopherol. J Food Sci 2007; 72(3): 207-211. 
13. Eltayeib A, Elaziz A. Physicochemical properties of Roselle (Hibiscus sabdariffa $\quad$ L.) seeds oil 10(Elrahad-1) in North Kordofan, Sudan. J Scientific Innov Res 2014; 3(6): 578-582.

14. Official Methods and Recommended Practices of the American Oil Chemists' Society, 5th ed., ed. D. Firestone, AOCS Press, Champaign, 1997.

15. Zarringhalami S, Sahari MA, Barzegar M, Hamidiesfehani Z. Changes in oil content, chemical properties, fatty acid composition and triacylglycerol species of tea seed oil during maturity period. J Food Biochem 2011; 35: 1161-1169 [in Persian].

16. Cissouma AI, Tounkara F, Nikoo M, Yang N, Xu X. Physicochemical properties and antioxidant activity of Roselle seed extracts. Adv J Food Sci Technol 2013; 5(11): 1483-1489.

17. Sultana B, Anwar F, Ashraf M. Effect of extraction solvent/technique on the antioxidant activity of selected medicinal plant extracts. Molecules 2009; 14: 21672180 .

18. Ahmed D, Khan MM, Saeed, R. Comparative analysis of phenolics, flavonoids, and antioxidant and antibacterial potential of methanolic, hexanic and aqueous extracts from adiantum caudatum leaves. Antioxidants 2015; 4: 394-409.

19. Stalikas CD. Extraction, separation, and detection methods for phenolic acids and flavonoids. J Sep Sci 2007; 30: 326-895.

20. Do QD, Angkawijaya AE, Tran- Nguyen PL, Huynh LH, Soetaredjo FE, Ismadji S, Yi-Hsu J. Effect of extraction solvent on total phenol content, total flavonoids content, and antioxidant activity of Limnophila aromatica. J Food Drug Anal 2013; 22(3): $1-7$.

21. Nzikou JM, Bouanga-Kalou G, Matos L, Ganongo-po FB, Mboungou-Mboussi PS, Moutoula FE, et al. Characteristics and nutritional evaluation of seeds oil from Roselle (Hibiscus sabdriffa L.) in CongoBrazzaville. Int J Biol Sci 2011; 3: 141-146.

22. Halimatul SMN, Amin I, Mohd N, Nawalyah AG, Siti MM. Protein quality of Roselle (Hibiscus sabdariffa L.) seeds. Asean Food J 2007; 14 (2):131-140.

23. Anel TC, Thokchom R, Subapriya MS, Jenita Thokchom J, Singh SS. Hibiscus sabdariffa - A natural micro nutrient source. Inter J Adv Res Biol Sci 2016; 3(4): 243-248.

24. Mariod A. A, Suryaputra S, Hanafi M, Rohmana T, Leonardus B.S, Kardono L. B, Tjahjono Herwan T. Effect of diffrent processing technioues on Indonesian Roselle (Hibiscus radiates) seed constituents. Acta Sci Pol Technol 2013; 12(4): 359-364.
25. Hainida E, Amin I, Normah H, Mohd N. Nutritional and amino acid contents of differently treated Roselle (Hibiscus sabdariffa L.) seeds. J Food Chem 2008; 111: 906-911.

26. Savage GP. Chemical composition of walnuts (Juglans regia L.) grown in New Zealand. J Hum Nutr 2001 ; 56(1): 75-82.

27. Atta BM, Imaizumi K. Some characteristics of crude oil extracted from Roselle (Hibiscus sabdariffa L.) seeds cultivated in Egypt. J Oleo Sci 2002; 51(7): 457-461.

28. Rehab FM, Ayman ME. Hypolipidemic and hypocholesterolemic effect of Roselle (Hibiscus sabdariffa L.) seeds oil in experimental Male rats. J Oleo Sci 2017; 66 (1):41-49.

29. Elneairy N. Comparative studies on Egyptian and Libyan Roselle seeds as a source of lipid and protein. Food Nutr Sci 2014; 5:2237-2245.

30. Fernández-Agulló A, Pereira E, Freire MS, Valentao P, Andrade PB, González-Álvarez J, Pereira JA. Influence of solvent on the antioxidant and antimicrobial properties of walnut (Juglans regia L.) green husk extracts. Ind Crops Prod 2013; 42: 126-132.

31. Prior R, Wu X, Schaich K. Standardized methods for the determination of antioxidant capacity and phenolics in foods and dietary supplements. J Agric Food Chem 2005; 53: 4290-4302.

32. Hashemi Z, Hojati M, Tahanezhad M. Evaluation of antioxidant activity of orange leaves (Citrus aurantium L.) compared with TBHQ synthetic antioxidant in edible oil. J Food Technol 1393; 2(6): 43-57. [In Persian].

33. Maizura M, Aminah A, Wan Aida WM. Total phenolic content and antioxidant activity of kesum (Polygonum minus), ginger (Zingiberofficinale) and turmeric (Curcuma longa) extract. Inter Food Res J 2011; 18: 529-534.

34. Tatiya AU, Tapadiya GG, Kotecha S, Surana SJ. Effect of solvents on total phenolics, antioxidant and antimicrobial properties of BrideliaretusaSprengstem bark. Indian J Nat Prod Resour 2011; 2 (4): 442-447.

35. Lapornik B, Prosek M, Wondra AG. Comparison of extracts prepared from plant byproducts using different solvents and extraction time. J Food Eng 2005; 71: 214-222.

36. Yilmaz Y, Toledo R. Oxygen radical absorbance capacities of grape/wine industry byproducts and effect of solvent type on extraction of grape seed polyphenols. J Food Compos Anal 2006; 19(1): 41-48.

37. Rimamcwe KB, Chavan UD. Antioxidant activity and nutritional value of Roselle seeds flour. Int J Curr Microbiol Appl Sci 2017; 6(4): 2654-2663. 